\title{
Study on the Model of Home Delivery of Fresh Food under New Retail
}

\author{
Zhuo Chen ${ }^{a}$, Mengya Zhang ${ }^{\text {b, }}{ }^{*}, Z_{i j i a ~ D u}{ }^{c}$ and Yong Cheng ${ }^{d}$ \\ School of Wuhan University of Technology, Wuhan430063, China. \\ a457218054@qq.com, b kmno40311@163.com, c2732004529@qq.com, d1106602584@qq.com
}

Keywords: New retail, Home delivery of fresh food, Last kilometer, Information sharing.

\begin{abstract}
In this paper, the home delivery mode of fresh food in chain supermarket under new retail was studied, including its operation model, organizational structure, business process, to find the best implementation model of the "last kilometer". At the same time, the cold chain logistics information system was constructed to meet the customer's purchase demand, and realize the information sharing of the stakeholders, such as suppliers, supermarket chains, distribution personnel, etc. and provide the basis for supermarket chains and related traditional retail enterprises to deal with the change of trade form.
\end{abstract}

\section{Introduction}

With the continuous improvement of people's living standards, consumers' demand for fresh agricultural products is transformed from quantity to quality, so that fresh food which is healthier, greener and safer is becoming more and more popular. [1]However, because fresh food has the characteristics of short preservation time, easy corruption and has high requirements for distribution time, preservation degree and service attitude, the traditional retail and e-commerce enterprises cannot meet the personalized needs of consumers. As a result, new retailing came into being. It integrates the innovative technologies of cloud computing, big data and artificial intelligence based on improving the traditional retail mode. It contacts with consumers with a brand-new look, meets customers 'needs, promotes consumption upgrading and technological reform.

Under the background of new retail, the paper studied the home delivery mode of fresh food (namely deliver the fresh and safe food to the designated site according to the customer's requirements) with the supermarket chains as the carrier and combining the online and offline modes, to find the best implementation model of the "last kilometer" for cold chain food. And then the paper constructed the cold chain logistics information system based on the analysis of the user's needs.

\section{Study on the Model of Home Delivery of Fresh Food Under New Retail}

There are two main problems in the home delivery of fresh food: (1) High distribution costs of the "last kilometer" for home delivery of fresh food; (2) Failure to meet customers' demand for delivery time. On this basis, the home delivery mode of fresh food in supermarket chains under new retail was studied, including its operation model, organizational structure, business process, to meet the customers' individual requirements, reduce the operating costs and solve the problem of the "last kilometer".

\subsection{Operation Model.}

Synthesizing the research on logistics distribution mode at home and abroad and combined with the characteristics of fresh food in perishable property and home delivery service timeliness, this paper constructs a cold chain logistics information system platform to enable suppliers to receive order information from the level I freight trading system and directly deliver the fresh food to the customer's designated locations through supermarkets. The supermarket chains establish a strategic cooperation relationship in the aspects of purchase, logistics and information, and construct the supermarket alliance. On the one hand, the members in the alliance appoint the professional purchasing personnel to construct the procurement alliance for fresh food, seek for the best suppliers of fresh food and reduce the purchase costs. On the other hand, the supermarkets may share the 
purchase information and market information in cold chain logistics information system platform. The supermarket sends the demand order to the cold chain logistics information system information platform according to the commodity demand information. The platform sends the distribution order to the distribution center, and the distribution center distributes the goods to the supermarkets according to the distribution order.

\subsection{Organizational Structure.}

The distribution under fresh food home delivery mode may combine the physical flow, capital flow and information flow. The customers place an order on the level II freight trading system according to the suppliers' information recommended by fresh food logistics information system. After receiving the order, the supermarket retails report the market information to level I freight trading system. After receiving the demand information, the suppliers directly send the fresh food to the customers' designated place via the supermarket retail point. At the same time, level II freight trading system also sets up a home delivery center in addition to the customer and supermarket transaction and distributes the goods according to the optimized distribution path. This model shortens the distribution time of fresh food and ensures the quality of fresh food. The organizational structure of the mode consists of the suppliers, level I freight trading system, supermarket retail point, home delivery center and customers. The structure is shown in Figure 1.

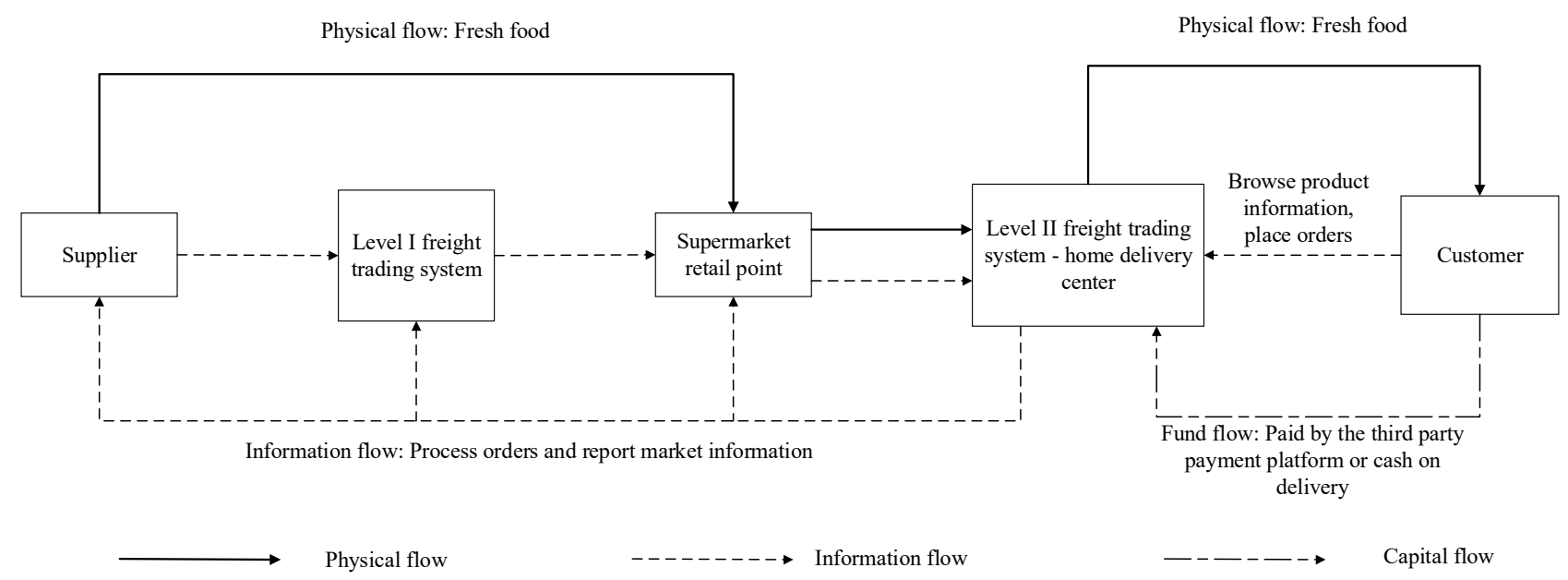

Figure 1. Schematic Diagram of Organizational Structure of Home Delivery Mode

(1) Freight trading system

Freight trading system is divided into level I freight trading system and level II freight trading system. Level I freight trading system mainly facilitates the communication between the members of procurement alliance of supermarket chains and the suppliers. The members of procurement alliance seek for the fresh food suppliers with better quality and low price according to the market demand information, purchase in batches to reduce the purchase costs. Level II freight trading system (home delivery center) mainly completes the transactions between supermarket chains and customers, receive the customers' feedback information, and meet the requirements for the customers' products and services to the largest extent.

(2) Supermarket retail point

The supermarket retail point is responsible for sending purchase orders to the procurement alliance according to the market demand. Meanwhile, it is responsible for sorting, packing and loading fresh foods and delivering them to the designated locations. To save delivery time, the distribution path can be optimized.

(3) Customer

Customers can make use of the merchant information recommended by the fresh food logistics information system to order fresh food in supermarket chains, select the time of distribution, and enjoy the preferential information of the merchants at the same time.

(4) Supplier 
According to the cold chain logistics information system, the supplier can restock the supermarket retail store in time.

\subsection{Business Flow Chart.}

With the help of enterprise data exchange, procurement demand is generated. Supermarket stores are stocked by purchase sharing mode. Customers can buy online or order information through fresh food logistics information system. After sorting and distribution, supermarkets create two sales online and offline routes. The specific flow is shown in Figure 2.

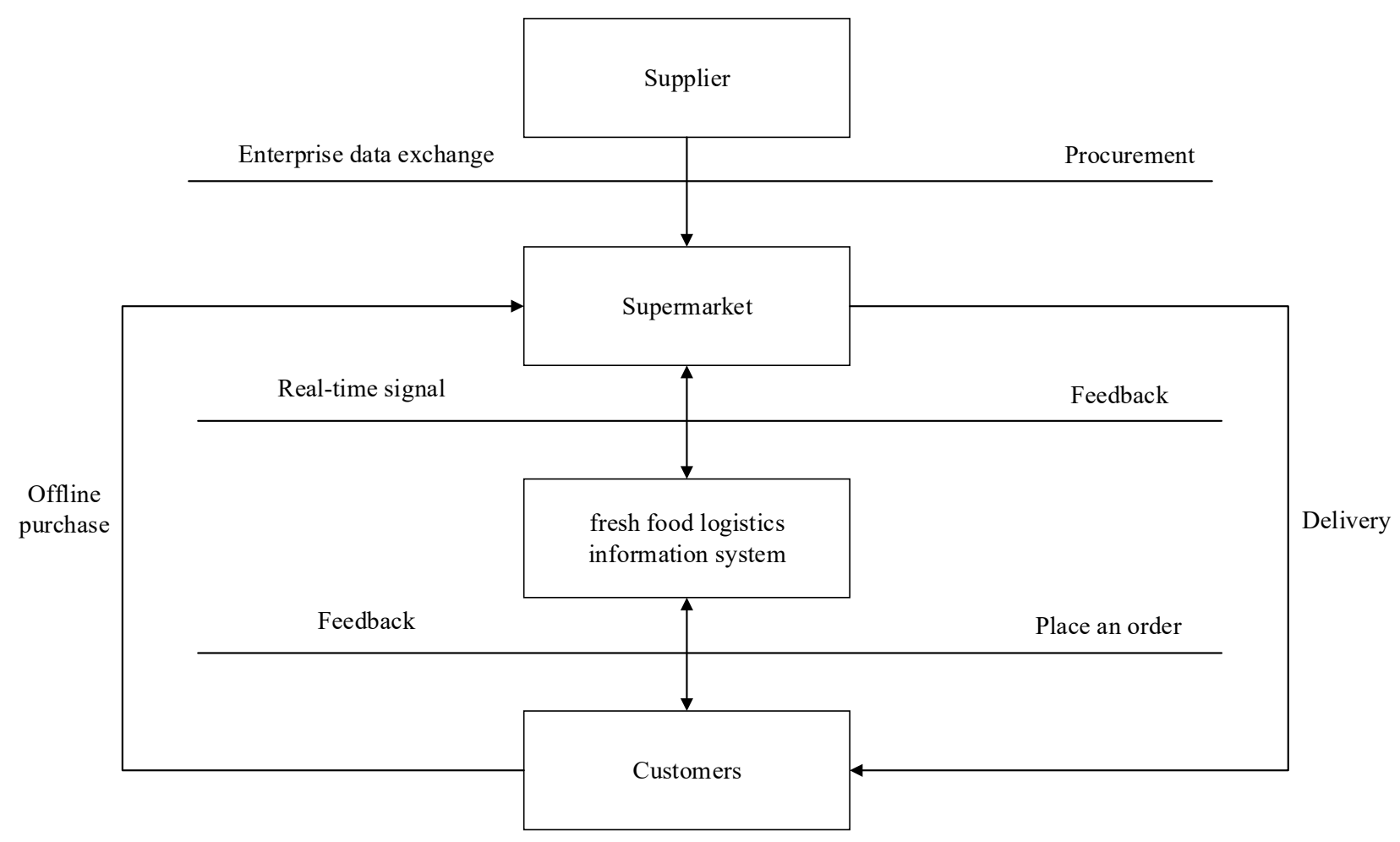

Figure 2. Business Flow Chart

(1) Purchase sharing: Through big data analysis, the enterprise predicts the customer demand, and report the data to the supermarket chains. The supermarket selects the way of purchase sharing to purchase from the supplier, to reduce the costs.

(2) Information sharing: Customers can order fresh food through fresh food logistics information system. The information system will feed back the customer purchase information to the supermarket. The supermarket carries on the timely distribution and may know the customer satisfaction through the customer feedback information, continuously update and optimize its services.

(3) Sorting and distribution: After receiving the customers' order, supermarket rapidly sorts them with barcode, RFID and other IOT technologies. Under the constraint of time window, supermarket arranges the distribution route, which may not only satisfy the customers, but also maximize the transportation rate, minimize the transportation costs and do a good job in fresh food home delivery $[2]$.

(4) Offline purchase: Customers can also purchase through the traditional way, that is, directly into the supermarket to purchase.

\section{Chapter III Construction of Cold Chain Logistics Information System under New Retail}

To construct a complete cold chain logistics information system, realize information sharing and avoid the problem of chain breakage in every link of fresh food, this chapter carries on the demand analysis and the overall design to it. 


\subsection{Demand Analysis}

Under the new retail environment, the optimized design cold chain logistics information system can provide various personalized demand information for stakeholders, such as suppliers, supermarket retail stores, etc., realize the sharing of information, and satisfy the consumer's timely demand for fresh food. Demand analysis of cold chain logistics information system platform mainly includes two aspects: User demand analysis and functional demand analysis.

\subsection{User Requirements Analysis}

The optimization design of cold chain logistics information system platform is to meet the needs of platform users. Therefore, the functions of the information platform must revolve around the needs of platform users. [3]First, we need to analyze the user types of the platform and then we can analyze their requirements. The objects of cold chain logistics information system mainly involve supplier, supermarket retail store and terminal consumer. These users have different emphasis on the demand of information service platform.

(1) Supplier: Suppliers include mainly manufacturers and fruit growers, and their demand for information platforms includes: Supermarket retail store demand and its location, cold storage stock, cold storage category, cold storage price, etc.

(2) Supermarket retail point: Supermarket retail stores mainly include various supermarket retail terminals. Most of them are close to the final consumer for the operation of fresh food. Their needs for information platforms include: Supplier information, goods information, goods source, goods value, consumer demand, consumer information, etc.

(3) End-consumers: Terminal consumers are the ultimate consumers, including individuals and groups. They accept online purchases of fresh food and have demand for them, and their demand for information platforms includes: commodity information, logistics status, delivery time, etc.

\subsection{Functional Requirements Analysis}

Through the above analysis, we understand the users' demand for cold chain logistics information system platform. To better realize the user's demand and make the information platform provide better service to the users, this paper analyzes the function of the cold chain logistics information system platform.

(1) Data exchange function Data exchange function is one of the essential functions of logistics park information platform. As mentioned earlier, information platform users include many manufacturing enterprises and supermarket retail stores. There will be a lot of information interaction between different users and between different transactions. At the same time, there is a lot of information interaction between the information platform and the outside system. This kind of information interaction often exists in the form of data. Therefore, the platform must have the function of data exchange to realize information exchange and sharing.

(2) E-commerce function the users of the information platform design many participants in the supply chain. They complete a series of business activities on the information platform. Therefore, the cold chain logistics information platform needs to have the function of electronic commerce, and provide users with the services of user identity authentication, online transaction, online settlement, credit evaluation, etc.

\subsection{Overall Design of Cold Chain Logistics Information System}

In the new retail environment, based on the characteristics of cold chain logistics and the demand analysis of information platform, the overall design of cold chain logistics information system is shown in Figure 3.

The system mainly includes four parts: cold chain logistics information management system, level I cold chain freight transportation transaction system, level II cold chain freight transportation transaction system, and internal operation management system. Level I trading system refers to transactions between suppliers and supermarket retailers. Level II trading system refers to the transaction between the supermarket retailers and the end consumers. Finally, a cold chain logistics information system is formed, which is centered on supermarket and connects upstream suppliers with terminal consumers. It is used to provide corresponding services for suppliers, supermarkets and final consumers. 


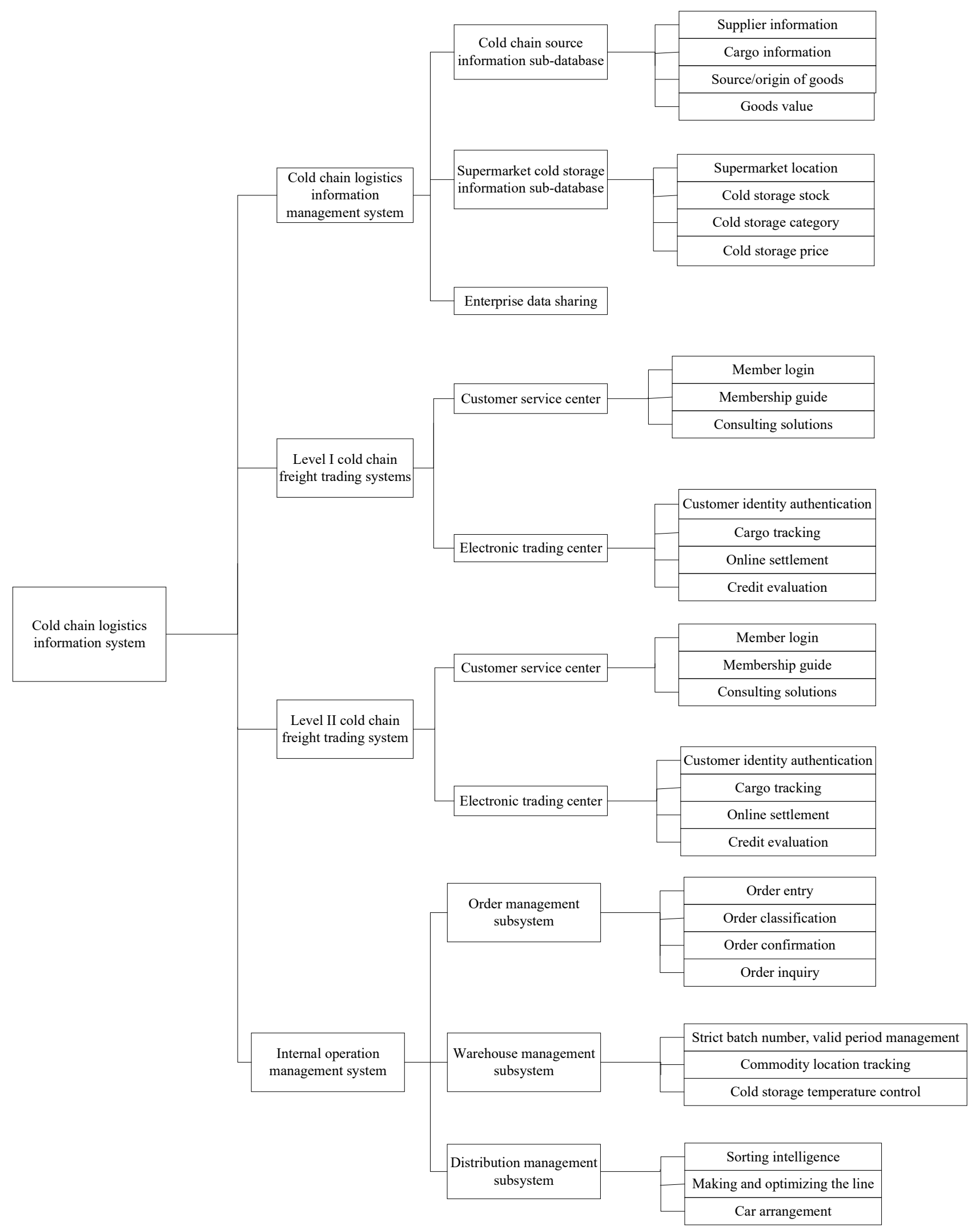

Figure 3. Overall Design of Cold Chain Logistics Information System

\section{Summary}

In this paper, the model of home delivery of fresh food in supermarket chains is studied, which makes fresh food distribute with the aid of supermarket chains and can save the cost of establishing cold chain logistics system and solve the problem of last kilometer and meet the customer's requirements for fresh food "quality". At the same time, the construction of chain supermarket fresh 
food logistics information system can realize the whole link of people, cars, goods, field online, strengthen the link of communication, avoid the problem of chain breakage, ensure the quality of fresh food. Therefore, this model is worth popularizing.

\section{References}

[1] Xu Guangshu, Song Zilong. Contract Coordination between Fresh Food Electronic Merchants and Logistics Service Providers - Analysis Based on the Pattern of Fresh Food Home Delivery [J]. Business Studies. 2017(02).

[2] Huang Qian. Research on the Model and Optimization of Home Delivery of Fruits and Vegetables in Cities [D]. Southwest Jiaotong University, 2010.

[3] Xu Xuecai, Luo Xiangjian, Sun Xun, Lan Jianhua. Construction of Railway Cold Chain Logistics Park Information Platform Based on Internet of Things [J]. Logistics Technology. 2017(03). 